\title{
Sinais clínicos, lesões e alterações produtivas e reprodutivas em caprinos intoxicados por Ipomoea carnea subsp. fistulosa (Convolvulaceae) que deixaram de ingerir a planta ${ }^{1}$
}

\author{
Carlos Alberto de Oliveira Júnior ${ }^{2}$, Franklin Riet-Correa ${ }^{3}$, Marcos Dutra Duarte ${ }^{2}$, \\ Valíria D. Cerqueira ${ }^{2}$, Cláudio Vieira Araújo ${ }^{4}$ e Gabriela Riet-Correa ${ }^{2 *}$
}

\begin{abstract}
Oliveira C.A., Riet-Correa F., Dutra M.D., Cerqueira D.V., Araújo C.V. \& Riet-Correa G. 2011. [Clinical signs, lesions and productive and reproductive changes in goats poisoned by Ipomoea carnea subsp. fistulosa (Convolvulaceae) that discontinued to ingest the plant.] Sinais clínicos, lesões e alterações produtivas e reprodutivas em caprinos intoxicados por Ipomoea carnea subsp. fistulosa (Convolvulaceae) que deixaram de ingerir a planta. Pesquisa Veterinária Brasileira 31(11):953-960. Programa de Pós-Graduação em Saúde Animal na Amazônia, Campus de Castanhal, Universidade Federal do Pará, Rua Maximino Porpino da Silva 1000, Pirapora, Castanhal, PA 68743080, Brazil. E-mail: griet@ufpa.br

The aim of this research was to study the clinical signs, productive and reproductive performance, and lesions of goats poisoned by Ipomoea carnea subsp. fistulosa after removal from the paddocks where the plant occurred. Thirty seven goats were divided into four groups: Group 1 consisted of 14 goats with poor body conditions and mild to severe nervous signs, acquired from a farm where the plant occurred; Group 2 (control) consisted of 10 goats which had also poor body conditions, but were acquired from a farm where the plant did not occur; Group 3 consisted of two goats with clinical signs of intoxication and which were slaughtered on the farm where they became poisoned; Group 4 consisted of 11 goats slaughtered as controls for the study of gross and histological lesions. The animals from Group 1 and 2 were evaluated for a period of 12 months on a farm located in the municipality of Castanhal/Pará, in a paddock where the plant did not occur. Six months later, the animals of Group 1 continued with poor body condition, rough hair coat, and nervous signs, especially intention tremors, what became with time less noticeable. In the same period, the goats of Group 2 gained an average of $13 \mathrm{~kg}$ body weight. Goats from Group 1 showed to be more susceptible to gastrointestinal parasites than those from Group 2. From the eight goats of Group 1 remaining on the farm only 4 became pregnant and delivered three kids which died shortly after birth, while all goats from Group 2 got pregnant and delivered healthy kids. At necropsy, two goats from Group 1 showed cerebellar atrophy. The main histological change observed in animals of Groups 1 and 3 was a decreased number of Purkinje cells in the cerebellum. It is concluded that goats chronically intoxicated by I. carnea and which discontinued to ingest the plant but showed still clinical signs, even though diminished in intensity, had poor productive and reproductive performance and were highly susceptible to gastrointestinal parasites. For economical reasons, it is suggested that farmers cull affected animals which show still nervous signs 15 days after the end of I. carnea consumption. The most common permanent clinical signs are intention tremors, probably due to the loss of Purkinje cells, what
\end{abstract}

\footnotetext{
${ }^{1}$ Recebido em 2 de março de 2011.

Aceito para publicação em 18 de julho de 2011.

${ }^{2}$ Programa de Pós-Graduação em Saúde Animal na Amazônia, Campus de Castanhal, Universidade Federal do Pará (UFPA), Rua Maximino Porpino da Silva 1000, Castanhal, PA 68743-080, Brasil. *Autor para correspondência: griet@ufpa.br
}

\footnotetext{
${ }^{3}$ Hospital Veterinário, Centro de Saúde e Tecnologia Rural, Campus de Patos, Universidade Federal de Campina Grande, Patos, PB 50700-000, Brasil.

${ }^{4}$ Universidade Federal de Mato Grosso, Instituto de Ciências Agrárias e Ambientais, Av. Alexandre Ferronato 1200, Setor Industrial, Sinop, MT 78550-000, Brasil.
} 
could be primarily responsible for the malnutrition of the goats, the resulting reproductive failure and increased susceptibility to gastrointestinal parasites.

INDEX TERMS: Poisonous plants, Ipomoea carnea, goats, plant poisoning, production losses, reproduction losses, susceptibility to parasites, morphometry, cerebellum.

RESUMO.- 0 objetivo deste trabalho foi acompanhar a evolução clínica, o desempenho produtivo e reprodutivo e descrever as lesões de caprinos intoxicados por Ipomoea carnea subsp. fistulosa após a retirada dos locais onde ocorre a planta. Para isso foram utilizados 37 caprinos, divididos em 4 grupos. 0 Grupo 1 era composto por 14 caprinos adquiridos em uma propriedade onde ocorria a planta e que apresentavam condição corporal ruim e sinais clínicos nervosos da intoxicação, que variavam de discretos a acentuados. 0 Grupo 2 era composto por 10 cabras adquiridas em uma propriedade onde não ocorria a planta e também apresentavam condição corporal ruim. 0 Grupo 3 era composto por dois caprinos com sinais clínicos da intoxicação, que foram abatidos na fazendo onde tinham se intoxicado. 0 Grupo 4 era composto por 11 caprinos que serviram como controle para o estudo das lesões macroscópicas e histológicas. Os animais dos Grupos 1 e 2 foram avaliados por um período de 12 meses em uma propriedade localizada no município de Castanhal, onde não ocorre a planta. Durante esse período os animais recebiam o mesmo manejo. Seis meses após, os animais do Grupo 1 continuavam com condição corporal ruim, pelo áspero, maior susceptibilidade à infestações por parasitas gastrintestinais e permaneciam com sinais nervosos. Nos animais que apresentavam sinais nervosos discretos houve diminuição desses sinais, principalmente do tremor de intenção, que passou a ser menos perceptível. Nesse mesmo período os caprinos do Grupo 2 ganharam, em média, $13 \mathrm{~kg}$. Das 8 cabras do Grupo 1 que permaneceram na propriedade experimental somente 4 emprenharam e pariram, sendo que 3 cabritos morreram logo após o nascimento, enquanto que todas as cabras do Grupo 2 emprenharam e pariram cabritos sadios. Nos encéfalos dos caprinos do Grupo 1, 3 e 4 foram realizados estudos histológico, morfológico e morfométrico. Macroscopicamente dois animais apresentaram atrofia cerebelar. No estudo morfométrico, as principais alterações histológicas observadas nos animais dos Grupos 1 e 3 foram diminuição dos neurônios de Purkinje do cerebelo. Conclui-se que caprinos cronicamente intoxicados por I. carnea que deixam de ingerir a planta apresentam sinais permanentes, mesmo que diminuídos de intensidade, fraco desempenho produtivo e reprodutivo e alta susceptibilidade aos parasitas gastrintestinais. Sugere-se que os produtores ao iniciar um plano de controle da intoxicação eliminem todos os animais que em um prazo de até 15 dias não apresentam regressão total dos sinais. 0 sinal permanente mais frequente é o tremor de intenção, associado à perda de neurônios de Purkinje, que poderia ser o principal responsável pela desnutrição dos animais e as conseqüentes falhas reprodutivas e maior susceptibilidade às parasitoses gastrintestinais.

TERMOS DE INDEXAÇÃO: Plantas tóxicas, Ipomoea carnea, caprinos, intoxicação por plantas, alterações produtivas, alterações reprodutivas, susceptibilidade aos parasitas, morfometria, cerebelo.

\section{INTRODUÇÃO}

Ipomoea carnea subsp. fistulosa é uma planta que causa doença de depósito lisossomal em ruminantes, principalmente caprinos (Armién et al. 2007, Riet-Correa \& Méndez 2007), mas que também afeta ovinos (Armién et al. 2011) e bovinos (Antoniassi et al. 2007). $O$ principio ativo de $I$. carnea subsp. fistulosa é o alcalóide indolizidínico swainsonina, que inibe a atividade das enzimas $\alpha$-manosidase lisossomal e $\alpha$-manosidase II do aparelho de Golgi (Balogh et al. 1999, Haraguchi et al. 2003). Na planta têm sido identificadas, também, calisteginas B1, B2, B3 e C1 (Haraguchi et al. 2003).

A intoxicação por I. carnea ocorre freqüentemente em caprinos na região Nordeste, principalmente no Vale do Rio São Francisco e no sul do Piauí (Armién et al. 2007, Riet-Correa \& Méndez 2007). Na região Norte, a intoxicação foi diagnosticada em caprinos na Ilha de Marajó (Oliveira et al. 2009). Nos município de Soure e Cachoeira do Arari, ocorre em todas as propriedades onde são criados caprinos, com prevalência de até $90 \%$. A intoxicação é observada durante todo o ano e é de extrema importância na região, pela baixa disponibilidade de forragem na época seca e pelo fato dos animais continuarem a ingerir a planta mesmo em períodos em que há pastagem disponível (Oliveira et al. 2009).

I. carnea permanece verde durante todo o ano e causa intoxicação principalmente em épocas de escassez de alimento (Tokarnia et al. 2000, Henrique 2002, Armién et al. 2007, Oliveira et al. 2009). Outra condição para a ocorrência da intoxicação é a existência de grandes quantidades da planta, pois os animais, para apresentarem sinais de intoxicação, precisam ingeri-la quase como alimento exclusivo durante semanas (Armién et al. 2007). Em geral a planta não é ingerida espontaneamente pelos animais, no entanto, animais intoxicados desenvolvem avidez pela mesma e fazem com que os outros animais a ingiram. Isso tem sido descrito por fazendeiros como vício, mas provavelmente se trate de facilitação social, processo pelo qual animais que não ingerem determinadas plantas aprendem a ingeri-las na presença de outros animais que a ingiram (Riet-Correa \& Méndez 2007).

Caprinos intoxicados podem apresentar sonolência, emagrecimento progressivo, pêlos arrepiados e sinais nervosos caracterizados por ataxia, hipermetria, paresia espástica, tremores de intenção, nistagmo, posição com base ampla e outras posturas anormais. Quando movimentados ou agitados os sinais são exacerbados podendo observar-se marcada incoordenação dos membros posteriores ou quedas (Riet-Correa \& Méndez 2007, Oliveira et al. 2009). 0 quadro de intoxicação pode ser revertido se os animais são retirados dos locais invadidos por I. carnea em até aproximadamente 30 dias após a observação dos primeiros sinais clínicos (Barbosa et al. 2007, Riet-Correa \& Méndez 2007). No entanto, em animais que continuam a ingerir a planta 
por períodos mais longos os sinais nervosos se tornam irreversíveis, em conseqüência da perda neuronal (Riet-Correa \& Méndez 2007).

Não se conhece tratamento para casos de intoxicação por I. carnea. Os criadores abatem os animais afetados para aproveitamento da carne, antes que esses emagreçam demais (Tokarnia et al. 2000). Os animais devem ser retirados imediatamente do local onde ocorre a planta. Como os animais desenvolvem preferência por ingerir esta planta que contém swainsonina deve ser recomendado que os que se intoxicam não retornem aos locais onde existe a planta, pois podem induzir a outros animais da mesma espécie a ingeri-la (Riet-Correa \& Méndez 2007).

O principal objetivo deste trabalho foi acompanhar a evolução clínica e o desempenho produtivo e reprodutivo de animais intoxicados por I. carnea após a retirada dos locais onde ocorre a planta. Com esta informação será possível determinar algumas medidas de controle da intoxicação, principalmente no referente a animais com sinais clínicos. Além disso, descrevem-se as lesões em caprinos intoxicados cronicamente.

\section{MATERIAL E MÉTODOS}

Para caracterizar a evolução dos sinais clínicos e as lesões de caprinos intoxicados por Ipomoea carnea subsp. fistulosa que deixaram de ingerir a planta foram utilizados 37 caprinos, divididos em 4 grupos.

O Grupo 1 era composto por 14 caprinos ( 11 cabras e 3 bodes) (C1 a C14), mestiços, com sinais clínicos sugestivos da intoxicação. Esses animais foram adquiridos em uma propriedade localizada no município de Soure, Ilha de Marajó, durante o período seco (novembro). Este grupo foi utilizado para estudar a reversibilidade dos sinais clínicos e das lesões, e para determinar as alterações produtivas e reprodutivas.

Os sinais clínicos nervosos nos animais intoxicados por I. carnea foram classificados em discretos, moderados ou acentuados. Sendo que animais com sinais nervosos discretos apresentavam tremores de intenção quando agitados, dismetria e ataxia discreta. Animais com sinais nervosos moderados apresentavam ataxia, hipermetria e tremores de intenção mesmo em repouso. Animais com sinais nervosos acentuados apresentavam, além dos sinais anteriores, paresia espástica, nistagmo, posição com base ampla, posturas anormais e marcada incoordenação dos membros posteriores e quedas quando movimentados.

O Grupo 2 era composto por 10 cabras (C15 a C24), mestiças, provenientes de uma propriedade localizada no município de Castanhal, onde não existe a planta. Este grupo foi mantido junto ao Grupo 1 para servir como controle.

0 Grupo 3 era composto por um bode jovem e uma cabra (C25 e C26), mestiços, provenientes de uma propriedade localizada no município de Soure, Ilha de Marajó, que apresentavam sinais clínicos moderados e discretos da intoxicação, respectivamente, e que foram abatidos para consumo na propriedade no final do período chuvoso (agosto). Durante o abate, foram coletados fragmentos de todos os órgãos da cavidade abdominal e torácica, encéfalo e medula espinhal. 0 material coletado foi fixado em formol a $10 \%$.

0 Grupo 4 era composto por 11 caprinos ( 3 cabras e 8 bodes) (C27 a C37), jovens, mestiços. Os animais deste grupo foram adquiridos em uma propriedade localizada no município de Castanhal, onde não ocorre a intoxicação, para servirem como controle no estudo das lesões macroscópicas e histológicas. Foram abati- dos para consumo e, durante o abate, foram coletados fragmentos de todos os órgãos da cavidade abdominal e torácica, encéfalo e medula espinhal. 0 material coletado foi fixado em formol a $10 \%$.

Os animais dos Grupos 1 e 2 foram transferidos para uma propriedade localizada no município de Castanhal, onde foram avaliados por um período de 12 meses. Durante esse período os animais recebiam o mesmo manejo. Eram soltos durante o dia para pastejo, sendo realizado rodízio entre duas pastagens, uma de $P$. maximum cv Tanzânia e outra de Brachiaria humidicola. Durante a noite eram recolhidos ao aprisco. Recebiam água e sal mineral à vontade e ração comercial, na proporção de $1 \%$ do peso vivo, uma vez ao dia. Foi mantido, juntamente com os animais dos Grupos 1 e 2, um reprodutor da raça Boer. Mensalmente era realizado controle parasitológico mediante coleta de fezes para realização de contagem de OPG (ovos por grama de fezes) e coprocultura e, se necessário, era realizada a vermifugação.

Os animais foram pesados ao chegar à propriedade e a cada 3 meses e observados diariamente. Também a cada 3 meses foi realizado exame clínico específico do sistema nervoso central nos animais do Grupo 1.

Os animais C3 e C4 foram eutanasiados com sinais clínicos acentuados 7 e 15 dias após a chegada a propriedade. Após 6 meses, o animal C5 do Grupo 1 foi eutanasiado. Aos 10 meses, os animais C6, C9 e C10 do Grupo 1 foram, também, eutanasiados. Todos os animais eutanasiados e 3 animais que morreram espontaneamente foram necropsiados, sendo coletados fragmentos de todos os órgãos da cavidade abdominal e torácica, encéfalo e medula espinhal. 0 material coletado foi fixado em formol a $10 \% \mathrm{e}$ processado rotineiramente para histologia. Os animais do Grupo 2 e dois animais do Grupo 1 (C13 e C14), com sinais nervosos discretos, permaneceram na propriedade.

Nos encéfalos dos animais dos Grupos 1, 3 e 4 foi realizado estudo morfológico, histológico e morfométrico. Para estudo morfológico foram utilizados os encéfalos de 4 caprinos do Grupo 1 (C6, C9, C10 e C12) e de todos os caprinos dos Grupos 3 e 4 . Foram avaliados o tamanho do encéfalo, altura do cerebelo com tronco encefálico, altura do cerebelo, peso do encéfalo e peso do cerebelo.

Foram avaliados histologicamente o encéfalo, a medula espinhal e demais órgãos coletados de 9 animais do Grupo 1 (C3, C4, C5, C6, C7, C9, C10, C11 e C12) e de todos os animais dos Grupos 3 e 4 . Os caprinos $\mathrm{C} 1$ e C2, mortos 3 dias após serem retirados das áreas com I. carnea, não foram avaliados histologicamente por apresentarem autólise. Os encéfalos, após a fixação, foram cortados transversalmente, coletando-se fragmentos do córtex frontal, temporal, parietal e occipital, núcleos da base, tálamo, tubérculos quadrigêmios anterior e posterior, cerebelo, pedúnculos cerebelares e ponte, tronco encefálico à altura do núcleo do trigêmeo e núcleos vestibulares e óbex. Os cerebelos foram cortados transversalmente de modo a coletar o verme e os hemisférios. Foram feitos, também, cortes transversais e longitudinais da medula cervical, torácica e lombar. As amostras foram incluídos em parafina, cortados a 5 $\mu \mathrm{m}$ e corados por Hematoxilina-Eosina. Nesses animais foi realizado, também, estudo morfométrico em dois cortes de cerebelo de cada animal. Em cada corte foram avaliadas 10 folhas cerebelares, sendo contado o número de neurônios de Purkinje e a espessura das camadas molecular e granular. Os neurônios de Purkinje foram contados levando em consideração uma área de $1500 \mu \mathrm{m}$ da folha, iniciando a medida no ápice da camada de células de Purkinje e indo em direção à substância branca. Em cada um desses campos foi avaliada, também, a espessura da camada molecular e granular das faces laterais. Todas as medidas foram realizadas com a utilização um software de análise de imagens MOTICAM 2300 3.0 M Pixel USB 2.0 acoplado em um microscópio Nikon Eclipse 50i (aumento de $4 x$ ) que, por sua vez, estava ligado a um computador. 
Para discriminação de diferenças estatísticas entre os grupos experimentais foi adotado o seguinte modelo estatístico: $Y_{i j k l}=\mu$ $+\mathrm{G}_{\mathrm{i}}+\mathrm{S}_{\mathrm{j}}+\mathrm{C}_{\mathrm{k}}+\varepsilon_{\mathrm{ijk},}$ onde $\mathrm{Y}_{\mathrm{ijkl}}$ é a variável resposta na l-ésima unidade experimental, no i-ésimo tratamento, j-ésimo sexo, na k-ésima categoria de idade, com o erro aleatório $\varepsilon_{\mathrm{ijkl}}$

Para as variáveis: média de neurônios de Purkinje nas folhas cerebelares, média do comprimento da camada granular (LE), média do comprimento da camada granular do ápice, do comprimento da camada granular (LD), média do comprimento da camada molecular (LE), média do comprimento da camada molecular do ápice e média do comprimento da camada molecular (LD), foram realizadas mudanças de escalas para a logarítmica, com objetivo de atender a pressuposição de normalidade, necessária para realização da análise de variância. Em todos os casos foi adotado o nível de significância de 0,05.

\section{RESULTADOS}

Quando adquiridos, os 14 animais do Grupo 1 estavam magros, tinham pelo áspero e apresentavam sinais clínicos nervosos caracterizados por ataxia, hipermetria, paresia espástica, tremores de intenção, nistagmo, posição com base ampla e posturas anormais. Quando movimentados ou agitados alguns animais apresentavam marcada incoordenação dos membros posteriores e quedas. Os animais $\mathrm{C} 1$ a C4 quando avaliados na propriedade de origem apresentavam sinais clínicos moderados, caracterizados por ataxia, hipermetria e tremores de intenção mesmo em repouso, mas os sinais se agravaram durante o transporte à propriedade experimental. o C1 e o C2 morreram 3 dias após a chegada na propriedade e os C3 e C4 foram eutanasiados in extremis e necropsiados aos 7 e 15 dias, respectivamente, após a chegada na propriedade. Os caprinos C5 a C8 também apresentavam sinais nervosos moderados. Os animais C9 a C14 apresentavam sinais nervosos discretos, caracterizados por tremores de intenção quando agitados, dismetria e ataxia discreta.

Seis meses após a chegada os 10 animais restantes (C5 a C14) que, ao chegarem, tinham média de peso de $21 \pm 4,4$ $\mathrm{kg}$, continuavam com a mesma condição corporal, com média de peso de $22 \pm 4,3 \mathrm{~kg}$ e com pelo áspero. Os que apresentavam sinais nervosos moderados permaneciam isolados dos demais. 0 C7 não se alimentava adequadamente e morreu 6 meses após a chegada. 0 C8 foi encontrado morto seis meses após a chegada. Os C5 e C6 permaneceram fracos, com sinais clínicos moderados, sendo eutanasiados 6 e 11 meses após o início do experimento, respectivamente. Nos animais que apresentavam sinais nervosos discretos (C9 a C14) houve diminuição desses sinais, principalmente do tremor de intenção, que passou a ser menos perceptível. 0 caprino $\mathrm{C} 12$, seis meses após a chegada, fraturou o membro anterior direito e, mesmo após o tratamento, permaneceu em decúbito lateral e morreu. 0 C11, oito meses após a chegada morreu devido a pleurite causada pela perfuração do tórax durante briga com os outros animais. O C9 e C10, mesmo 11 meses após a chegada à propriedade, permaneciam magros e foram eutanasiados.

Das 8 cabras do Grupo 1 que permaneceram na propriedade experimental somente 4 emprenharam e pariram, sendo que 3 cabritos nasceram fracos, não ingeriram o colostro ou ingeriam pouca quantidade, e morreram logo após o nascimento.
As dez cabras do Grupo 2 quando adquiridas tinham condição corporal ruim, com média de peso de $27 \pm 3 \mathrm{~kg}$. Seis meses após, a condição corporal era boa e a média de peso era de 40,5 $\pm 4,1 \mathrm{~kg}$. Após a chegada todas as cabras emprenharam e pariram, sendo que 6 tiveram parto gemelar. Dos 16 cabritos, um nasceu morto e dois, filhos da mesma cabra, morreram devido a traumatismos por pisoteio.

Nos exames parasitológicos mensais os animais dos Grupos 1 e 2 apresentavam número semelhante de ovos por grama (OPG). Na coprocultura Haemonchus contortus foi o principal parasita, representando em média $69 \%$ das larvas. Outros parasitas encontrados, com menor freqüência, foram Tricostrongylus spp. No entanto, quando as amostras de fezes do Grupo 1 superavam os 1000 OPG muitos animais já demonstravam sinais clínicos de infecção por Haemonchus contortus caracterizados por debilidade, anorexia e mucosas acentuadamente pálidas, sendo necessário realizar, além do tratamento anti-helmíntico, tratamento de suporte com fluidoterapia (solução composta por vitaminas, aminoácidos e sais minerais); enquanto que os animais do Grupo 2 com OPG semelhantes apresentavam somente discreto emagrecimento.

Os animais C25 e C26 do Grupo 3 apresentavam sinais nervosos moderados e discretos, respectivamente, sugestivos da intoxicação por I. carnea.

$\mathrm{Na}$ necropsia dos animais C3, C4, C5, C6, C7, C9, C10, C11 e C12 havia quantidades moderadas de Haemonchus contortus no abomaso. No animal C6 (Grupo 1) e C26 (Grupo 3) o cerebelo era evidentemente menor que o normal (Fig.1).

Histologicamente o C3, que tinha sinais nervosos acentuados e morreu logo após a chegada à propriedade experimental, e o C25, que tinha sinais nervosos moderados, apresentavam vacuolização acentuada do pericário de neurônios do sistema nervoso central, mais marcada nas células de Purkinje do cerebelo, núcleos cerebelares e outros núcleos do tronco encefálico. Alguns neurônios do cerebelo e dos núcleos cerebelares apresentavam núcleos picnóticos e marginalizados e citoplasma espumoso e pálido sem

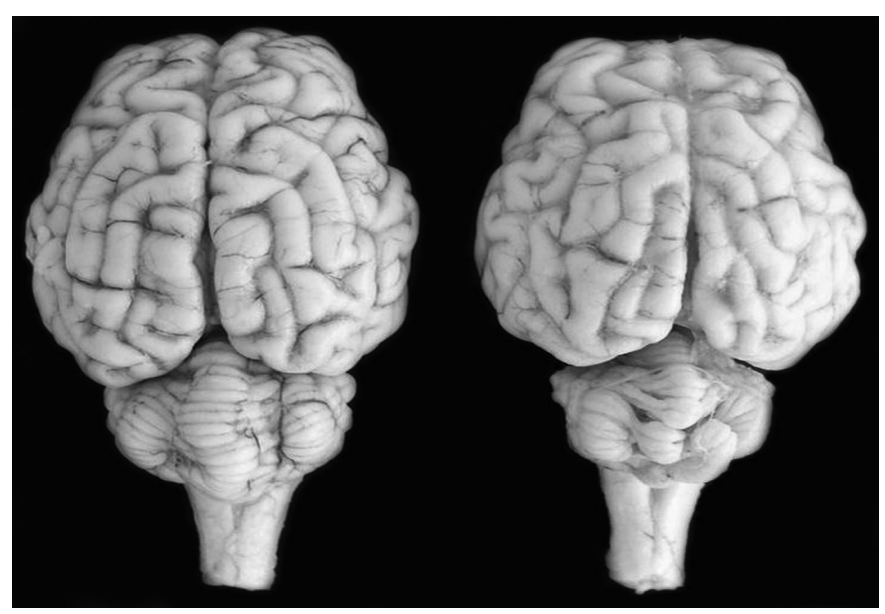

Fig.1. Intoxicação por Ipomoea carnea subsp. fistulosa. À esquerda observa-se o encéfalo de um caprino controle. À direita o encéfalo do caprino C26 que apresentava atrofia do cerebelo. 
bordas definidas (Gost cells=células fantasmas). Degeneração Walleriana, caracterizada pela presença de numerosos esferóides axonais, eram observados, principalmente na substância branca cerebelar e pedúnculos cerebelares. Havia, também, vacuolização do citoplasma de células epiteliais dos rins, fígado e pâncreas.

Nos demais animais dos Grupos 1 e 3 as alterações observadas foram diminuição dos neurônios de Purkinje do cerebelo, com proliferação da glia de Bergmann (Fig.2) e, na substância branca cerebelar, degeneração Walleriana caracterizada pela presença de esferóides axonais e vacúolos (elipsóides de mielina), alguns contendo restos axonais e raros macrófagos no seu interior (Fig.3).

Nos animais do Grupo 1 e 3 a média de neurônios de Purkinje nos campos avaliados variou de 17 a 32 células por campo, enquanto que nos animais do Grupo 4 as médias foram de 39 a 53 células por campo.

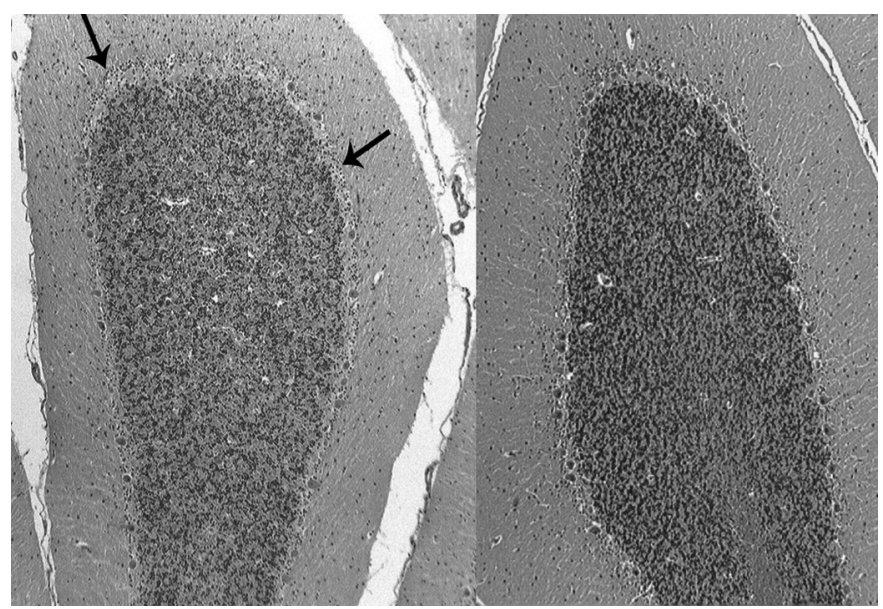

Fig.2. Intoxicação por Ipomoea carnea subsp. fistulosa. Cerebelo. À esquerda observa-se a folha cerebelar do caprino C10, que apresentava menor número de células de Purkinje e proliferação da glia de Bergmann (setas). À direita a folha cerebelar de um caprino controle. HE, obj.10x.

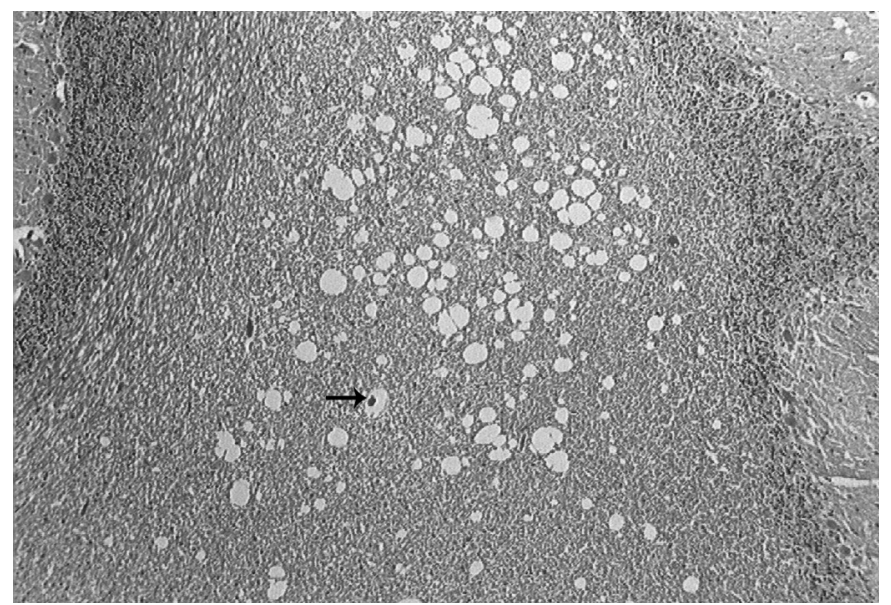

Fig.3. Degeneração Walleriana, caracterizada pela presença de numerosos vacúolos (elipsóides de mielina) no cerebelo, alguns contendo esferóides ou restos axonais, na intoxicação por Ipomoea carnea subsp. fistulosa de caprino. HE, obj.20x.
O Quadro 1 mostra a identificação, sexo, categoria animal, gravidade dos sinais nervosos, período de permanência na propriedade sem ter acesso a planta, desfecho clínico, proporção encéfalo:cerebelo e média de células de Purkinje nas folhas cerebelares dos animais dos grupos 1, 3 e 4.

Nas análises estatísticas das variáveis métricas o Grupo 1 apresentou menor valor médio no logarítimo para a variável média de neurônios de Purkinje nas folhas cerebelares $(\mathrm{P}<0,01)$ em relação aos indivíduos do Grupo 4. Para as demais variáveis estudas não houveram diferenças estatísticas entre grupos experimentais $(\mathrm{P}>0,05)$.

\section{DISCUSSÃO}

Dos 14 caprinos do Grupo 1, todos com sinais clínicos, que permaneceram na propriedade experimental sem acesso a planta, 4 morreram espontaneamente. Seis meses após pararem de ingerir a planta nenhum animal havia recuperado a condição corporal, mesmo recebendo uma boa nutrição. Em compensação, os animais do Grupo 2 (não intoxicados), que recebiam o mesmo manejo e que também foram adquiridos em condições corporais ruins, no mesmo período, ganharam peso e estavam em boas condições corporais. É provável que apesar de que os animais não apresentarem, aparentemente, dificuldade de locomoção e a alimentação era abundante, o sinal clínico responsável por essa desnutrição seja o tremor de intenção, visto que esses tremores aumentam quando os animais tentam se alimentar. Os tremores de intenção, que em maior ou menor grau permaneceram em todos os animais intoxicados, ocorrem, aparentemente, em conseqüência do desaparecimento de neurônios de Purkinje.

Apesar de não terem sido observadas alterações histológicas em nenhum dos órgãos analisados, além das lesões cerebelares, que justificassem a desnutrição, alterações permanentes em outros órgãos ou em outras regiões do SNC não podem ser descartadas como causa da desnutrição. Em animais recentemente intoxicados por locoweeds, plantas que também contém swainsonina, perda de peso e emaciação foram atribuídas a distúrbios gastrintestinais e metabólicos, incluindo alterações da secreção de enzimas digestivas e reflexo gastrintestinal alterado (Stegelmeier et al. 1999). Ainda, essa perda de peso pode ser um efeito da toxicidade da swainsonina inibindo diretamente ou alterando a produção de glicosidases intestinais, especialmente a sucarase (Stegelmeier et al. 1995). Henrique (2005) relaciona a diminuição do peso e do ganho de peso total em fêmeas caprinas tratadas com Ipomoea carnea à dificuldade locomotora e, conseqüentemente, ao acesso ao alimento. Esse autor verificou, também, diminuição no número de hemácias e na porcentagem do hematócrito nos animais experimentais, atribuindo essas alterações ao efeito tóxico da swainsonina, que promoveria a formação de um tipo híbrido de glicoproteínas nas membranas das células eritrocitárias, levando à eritropoese ineficaz. Outras alterações relatadas foram o aumento significante nos níveis séricos de ALT e AST, a diminuição nos níveis séricos de colesterol e o aumento nos níveis séricos de creatinina. Em um experimento com Astragalus mollisimus var. mollisimus em bovinos os valores da bioquímica sérica e urianálises não 


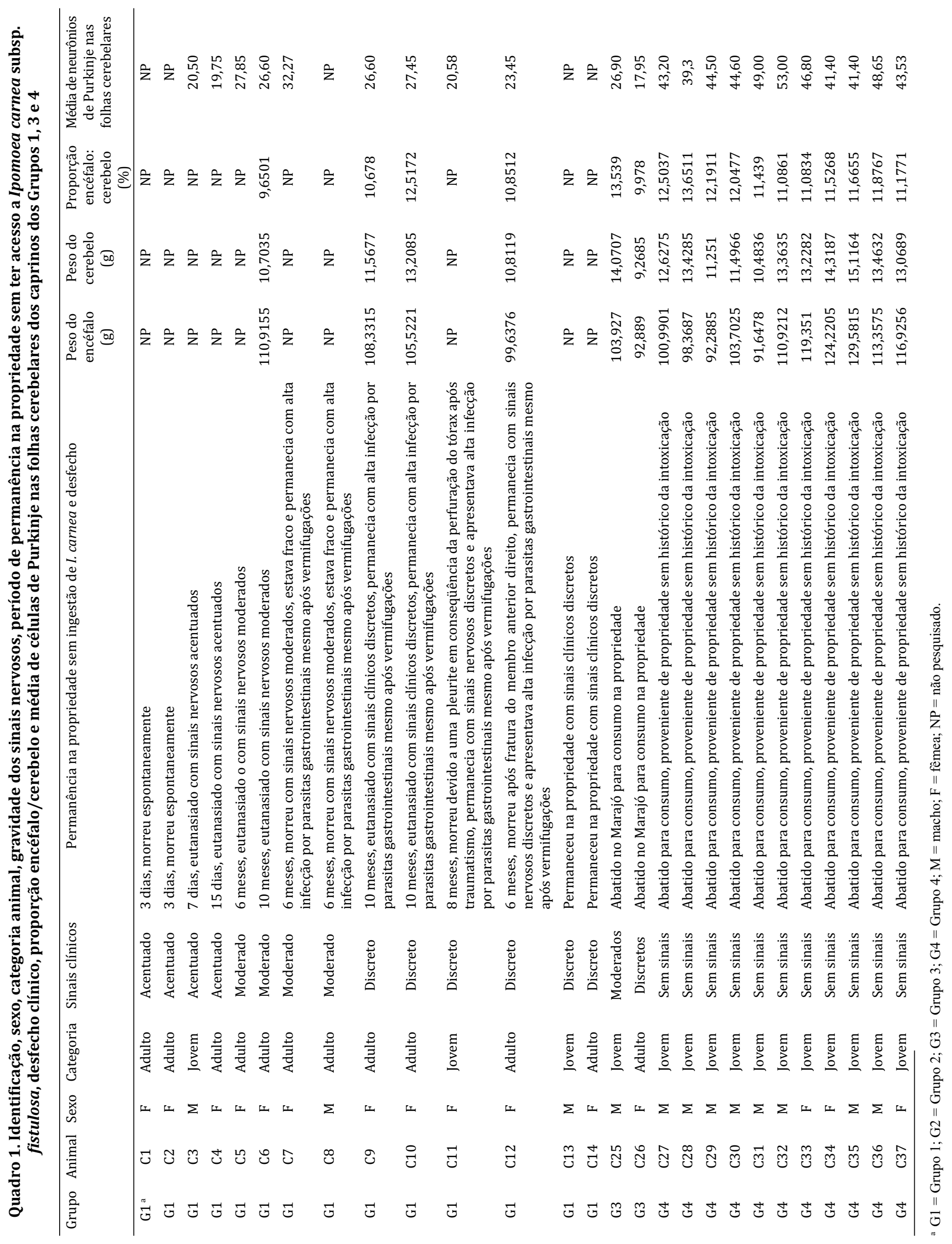


tiveram alterações, exceto pela hipoalbuminemia, devida, provavelmente, à perda de proteína associada à lesão renal e aos baixos valores séricos de hormônios da tireóides, especialmente T3, que eram correlacionados com as doses de swainsonina ingeridas (Stegelmeier et al. 1994). No entanto, Barbosa et al. (2007), não observaram alterações significantes no número de eritrócitos e leucócitos, hemoglobina, volume corpuscular médio, concentrações séricas de glicose, proteínas totais e albumina e nas atividades séricas de gama glutamiltransferase e aspartato aminotransferase em caprinos ingerindo Ipomoea sericophylla e Ipomoea riedelii.

A presença de sinais clínicos de hemoncose em caprinos do Grupo 1, com OPG semelhantes aos caprinos do Grupo 2 que não apresentavam sinais clínicos, sugere uma maior susceptibilidade às parasitoses gastrintestinais dos animais com sinais clínicos permanentes. Essa maior susceptibilidade deve-se, provavelmente, à desnutrição, pois carências alimentares aumentam a susceptibilidade aos parasitas gastrintestinais (Torres-Acosta \& Hoste 2008, Costa et al. 2011). A intoxicação por locoweeds pode prejudicar várias funções imunes, incluindo proliferação de linfócitos, linfócitos citotóxicos e expressão linfocitária de receptores de interleucina. Isso sugere que animais cronicamente intoxicados são mais susceptíveis a várias doenças infecciosas (Stegelmeier et al. 1995).

Outro fator importante é que todas as cabras do Grupo 2 emprenharam e pariram cabritos saudáveis, que mamavam logo após o nascimento e se desenvolveram bem, com exceção de um cabrito que nasceu morto. As outras duas mortes neonatais que ocorreram no Grupo 2 foi de cabritos gêmeos, que nasceram saudáveis e mamaram logo após o nascimento, mas morreram devido a pisoteio pelos outros animais. Por outro lado, das 8 cabras do Grupo 1, apenas 4 pariram; os cabritos eram fracos e 3 morreram imediatamente após o parto. Gotardo et al. (2011) relatam que alterações comportamentais observadas em filhotes provenientes de mães tratadas com I. carnea, comprometem significativamente a ingestão de colostro, diminuindo a imunidade passiva, que é determinante para a sobrevivência do recém-nascido. Astragalus spp., Oxitropis spp. (locoweeds) e I. carnea afetam seriamente a reprodução de animais de criação. É relatado que filhotes de ovelhas ingerindo locoweeds (James 1976) e de ratas ingerindo I. carnea (Schwarz et al. 2003) durante a gestação mostram-se fracos e com hiperflexão das articulações do carpo dos membros torácicos. Henrique (2005) relata o nascimento de cabritos com malformações, caracterizados por retrognatia, artrogripose e contratura congênita múltipla, indicando que $I$. carnea promove efeitos teratogênicos em caprinos. Ratas alimentadas durante a gestação com I. carnea apresentam alta reabsorção embrionária e alta mortalidade perinatal. Os filhotes nascidos mostram-se menores e com menor peso (Schwarz et al. 2003). Colodel et al. (2002) relataram o nascimento de animais fracos na intoxicação por Sida carpinifolia em caprinos. Entretanto, os autores sugerem que embora alterações reprodutivas possam ser comuns durante o consumo de Sida carpinifolia, o ciclo reprodutivo pode voltar ao normal após a restrição do consumo da planta, pois animais que deixam de ingerir a planta foram capazes de gerar produtos normais. É possível que a baixa natalidade e a alta mortalidade perinatal nos animais do Grupo 1 seja devido a desnutrição das mães, o que levaria à infertilidade ou ao nascimento de cabritos fracos que não ingerem o colostro e morrem poucos dias após o nascimento, já que as cabras não ingeriram a planta durante toda a gestação.

A regressão total ou parcial dos sinais clínicos é um aspecto importante a ser levado em consideração no controle da intoxicação por plantas que contem swainsonina. Seitz et al. (2005) sugerem que animais naturalmente afetados pelo consumo de Sida carpinifolia podem se recuperar quando retirados de áreas invadidas pela planta, uma vez que um ovino que ingeriu a planta por um período de 80 dias apresentou regressão de sinais clínicos e ausência de alterações patológicas 11 dias após parar o consumo. No entanto, Colodel et al. (2002) relatam que em caprinos intoxicados por Sida carpinifolia não há reversão do quadro após o consumo da planta. Dantas et al. (2007) observaram diminuição dos sinais clínicos em caprinos que consumiram Turbina cordata por um período de 94 dias, sendo que os sinais residuais 90 após o final da ingestão eram marcha lateral, moderado tremor de intenção, hipermetria e quedas após o teste de levantar a cabeça. Barbosa et al. (2007) sugerem que lesões irreversíveis devidas à perda neuronal ocorrem em cabras que continuam a ingerir plantas contendo swainsonina por aproximadamente 30 dias após o início dos sinais. Antes desse período não haveria perda neuronal e as lesões do SNC seriam reversíveis. A recuperação total de animais intoxicados recentemente ocorre dentro de 15 dias após o fim da ingestão (Barbosa et al. 2007). No presente trabalho houve melhora dos sinais nervosos, mais marcada nos animais que apresentavam sinais discretos; no entanto não ocorreu reversão total, permanecendo, principalmente, os tremores de intenção, que passaram a ser menos perceptíveis.

Neste trabalho, as principais lesões observadas nos animais que tinham deixado de ingerir a planta foi a atrofia cerebelar, observada em dois animais, e o desaparecimento das células de Purkinje, com proliferação da glia de Bergmann e degeneração Walleriana, observada em todos os animais afetados. 0 desaparecimento das células de Purkinje, seguida por degeneração Walleriana, proliferação de células da glia de Bergmann e atrofia cerebelar é característica da intoxicação crônica por plantas que contem swainsonina (Barbosa et al. 2006) e da intoxicação por Solanum fastigiatum var. fastigiatum (Rech et al. 2006) e por Solanum paniculatum (Guaraná et al. 2011). Essa semelhança sugere que a intoxicação por Solanum spp. deve ser incluída no diagnóstico diferencial da intoxicação por plantas que contêm swainsonina, principalmente em animais que deixaram de ingerir a planta e permanecem com sinais nervosos.

Dos animais que morreram ou foram eutanasiados após a chegada à propriedade apenas o $\mathrm{C} 3$, eutanasiado sete dias após a retirada dos locais onde estava ingerindo a planta, apresentou a vacuolização característica da intoxicação em neurônios e outras células. Os demais animais, incluindo o C4, eutanasiado 15 dias após a retirada das pastagens com I. carnea, não apresentavam vacuolização de neurônios ou outras células, demonstrando a reversibilidade dessas 
lesões. Por outro lado, todos os animais apresentavam diminuição no número de células de Purkinje (Quadro 1). Também foi observado vacuolização no animal C25, abatido numa fazenda onde ocorria a doença, que apresentava sinais clínicos moderados (C25); enquanto que no C26 que apresentava sinais clínicos discretos, foi observado apenas diminuição do número de células de Purkinje, sugerindo que tinha deixado de ingerir a planta. Destes dois animais do Grupo 3, abatidos na época das chuvas, o que apresentava sinais clínicos moderados e lesões de vacuolização (C25) era jovem, enquanto que o que tinha sinais clínicos discretos e diminuição dos neurônios de Purkinje, sem vacuolização (C26), era adulto. Em trabalhos experimentais de controle da intoxicação observa-se que caprinos adultos deixam de ingerir a planta, ou a ingiram em pouca quantidade, durante o período chuvoso (Oliveira et al. 2010. Dados não publicados). A determinação dos fatores que determinam a ingestão da planta é importante para se estabelecer medidas de controle da intoxicação.

Pelos resultados deste trabalho conclui-se que caprinos cronicamente intoxicados por I. carnea subsp. fistulosa que deixaram de ingerir a planta apresentam sinais permanentes, mesmo que diminuídos de intensidade, fraco desempenho produtivo e reprodutivo e alta susceptibilidade aos parasitas gastrintestinais. Portanto sugere-se que os produtores ao iniciar um plano de controle da intoxicação eliminem todos os animais que em um prazo de até 15 dias não apresentam regressão total dos sinais. 0 sinal permanente mais frequente é o tremor de intenção, associado à perda de neurônios de Purkinje, que poderia ser o principal responsável pela desnutrição dos animais e as conseqüentes falhas reprodutivas e maior susceptibilidade às parasitoses gastrintestinais.

Agradecimentos.- Trabalho financiado pelo Instituto Nacional de Ciência e Tecnologia Para o Controle das Intoxicações por Plantas (CNPq Proc. 573534/2008-0). Os autores agradecem aos professores Alessandra Scofield e Gustavo Góes Cavalcante pela realização dos exames parasitológicos.

\section{REFERÊNCIAS}

Antoniassi N.A.B., Ferreira E.V., Santos C.E.P., Campos J.L.E., Nakazato L. \& Colodel E.M. 2007. Spontaneous Ipomoea carnea subsp. fistulosa (Convolvulaceae) poisoning of cattle in the Brazilian Pantanal. Pesq. Vet. Bras. 27(10):415-418.

Armién A.G., Tokarnia C.H., Peixoto P.V. \& Freese K. 2007. Spontaneous and experimental glycoprotein storage disease of goats induced by Ipomoea carnea subsp fistulosa (Convolvulaceae). Vet. Pathol. 44:170-184.

Armién A.G., Tokarnia C.H., Peixoto P.V. \& Freese K. 2011. Clinical and morphological changes in ewes and fetuses poisoned by Ipomoea carnea subspecies fistulosa. J. Vet. Diagn. Invest. 23:221-232.

Balogh K.K., Dimande A.P., Van Der Lugt J.J., Molyneux R.J., Naude T.W. \& Welman W.G. 1999. A lysosomal storage disease induced by Ipomoea carnea in goats in Mozambique. J. Vet. Diag. Invest. 11(3):266-273.

Barbosa R.C., Riet-Correa F., Medeiros R.M.T., Lima E.F., Barros S.S., Gimeno J.E., Molyneux R.J. \& Gardner D.R. 2006. Intoxication by Ipomoea sericophylla and Ipomoea riedelii in goats in the state of Paraíba, Northeastern Brazil. Toxicon 47:371-379.

Barbosa R.C., Riet-Correa F., Lima E.F., Medeiros R.M.T., Guedes K.M.R, Gardner D.R., Molyneux R.J. \& Melo L.E.H. 2007. Experimental swainsonine poisoning in goats ingesting Ipomoea sericophylla and Ipomoea riedelii (Convolvulaceae). Pesq. Vet. Bras. 27(10):409-414.

Colodel E.M., Driemeier D., Loretti A.P., Gimeno E.J., Traverso S.D., Seitz A.L.
\& Zlotowski P. 2002. Aspectos clínicos e patológicos da intoxicação por Sida carpinifolia (Malvaceae) em caprinos no Rio Grande do Sul. Pesq. Vet. Bras. 22(2):51-57.

Costa V.M.M., Simões S.V.D. \& Riet-Correa F. 2011. Controle das parasitoses gastrintestinais em ovinos e caprinos na região semiárida do Nordeste do Brasil. Pesq. Vet. Bras. 31(1):65-71.

Dantas A.F.M., Riet-Correa F., Gardner D.R., Medeiros R.M.T., Barros S.S., Anjos B.L. \& Lucena R.B. 2007. Swainsonine-induced lysosomal storage disease in goats caused by the ingestion of Turbina cordata in Northeastern Brazil. Toxicon 49:111-116.

Gotardo A.T., Pfister J.A., Barbosa-Ferreira M. \& Górniak S.L. 2011. Neonate behavior in goats is affected by maternal ingestion of Ipomoea carnea, p.302-308. In: Poisonings by Plants, Mycotoxins and Related Substances. Riet-Correa F., Pfister J., Schild A.L. \& Wierenga T. (Eds), CAB International, London.

Guaraná E.L.S., Riet-Correa F., Mendonça C.L., Medeiros R.M.T., Costa N.A. \& Afonso J.A.B. 2011. Intoxicação por Solanum paniculatum em bovinos. Pesq. Vet. Bras. 31(1):59-64.

Haraguchi M., Gorniak S.L., Ikeda K., Minami H., Kato A., Watson A.A., Nash R., Molyneux R.J. \& Asano N. 2003. Alkaloidal components in the poisonous plant Ipomoea carnea (Convolvulaceae). J. Agric. Food Chem. 51:4995-5000.

Henrique B.S. 2002. Estudo dos efeitos tóxicos da administração prolongada de Ipomoea carnea em caprinos. Dissertação de Mestrado. Faculdade de Ciências Farmacêuticas, Universidade de São Paulo. São Paulo. 96p.

Henrique B.S. 2005. Efeitos tóxicos de Ipomoea carnea em caprinos: estudos da teratogenicidade. Tese de Doutorado, Faculdade de Ciências Farmacêuticas, Universidade de São Paulo. São Paulo. 156p.

James L.F. 1976. Effect of locoweed (Astragalus ientiginosus) feeding of fetal lamb development. Can. J. Comp. Med. 40(4):380-384.

Oliveira C.A., Barbosa J.D., Duarte M.D., Cerqueira V.D., Riet-Correa F. \& Riet-Correa G. 2009. Intoxicação por Ipomoea carnea subsp. fistulosa (Convolvulaceae) em caprinos na Ilha de Marajó. Pesq. Vet. Bras. 29(7):583-588.

Rech R.R., Rissi D.R., Rodrigues A., Pierezan F., Piazer J.V.M., Kommers G.D. \& Barros C.S.L. 2006. Intoxicação por Solanum fastigiatum (Solanaceae) em bovinos: epidemiologia, sinais clínicos e morfometria das lesões cerebelares. Pesq. Vet. Bras. 26:183-189.

Riet-Correa F. \& Méndez M.D.C. 2007. Intoxicação por plantas e micotoxinas, p.99-219. In. Riet-Correa F., Shild A.L., Lemos A.A. \& Borges J.R. (Eds), Doenças de Ruminantes e Eqüídeos. Vol. 2. 3aㅡ ed, Pallotti, Santa Maria. 694p.

Schwarz A., Górniak S.L., Bernardi M.M., Dagli M.L.Z. \& Spinosa H.S. 2003. Effects of Ipomoea carnea aqueous fraction intake by dams during pregnancy on the physical and neurobehavioral development of rat offspring. Neurotoxicology and Teratology 25(5):615-626.

Seitz A.L., Colodel E.M., Barros S.S. \& Driemeier D. 2005. Experimental poisoning by Sida carpinifolia (Malvaceae) in sheep. Pesq. Vet. Bras. 25(1):15-20.

Stegelmeier B.L., Ralphs M.H., Gardner D.R., Molyneux R.J. \& James L.F. 1994. Locoweed intoxication in range cattle and sheep: Serum a-mannosidase activity and clinicopathologic, p.501-506. In: Colegate L.M. \& Dorling P.R. (Eds), Plant-Associated Toxins: Agricultural, phytochemical and ecological aspects. CABI Publishing, Wallingford, UK.

Stegelmeier B.L., Molyneux R.J., Elbein A.D. \& James L.F. 1995. The lesions of locoweed (Astragalus mollissimus) swainsonine, and castanospermine in rats. Vet. Pathol. 32:289-298.

Stegelmeier B.L., James L.F., Panter K.E., Ralphs M.H., Gardner D.R., Molyneux R.J. \& Pfister J.A. 1999. The pathogenesis and toxicokinetics of locoweed (Astragalus and Oxytropis subsp.) poinsoning in livestock. J. Nat. Toxins 8:35-45.

Tokarnia C.H., Döbereiner J. \& Peixoto P.V. 2000. Plantas que causam perturbações nervosas, p.120-124. In: Ibid. (Eds), Plantas Tóxicas do Brasil. Ediora Helianthus, Rio de Janeiro.

Torres-Acosta J.F.J. \& Hoste H. 2008. Alternative or improved methods to limit gastro-intestinal parasitism in grazing sheep and goats. Small Rum. Res. 77:159-173. 